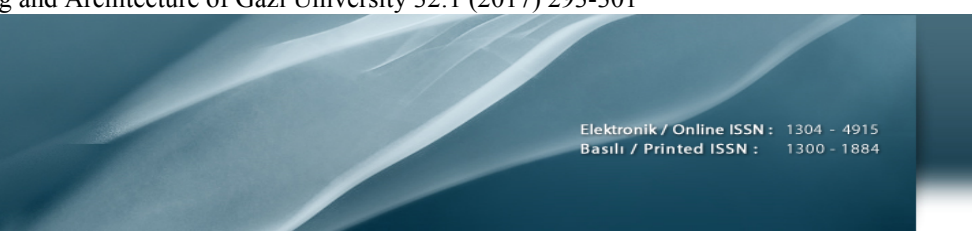

\title{
Havacılık ve uzay malzemelerinde soğutma sıvısının elektro erozyonla delinen deliklerin performans parametrelerine etkisinin deneysel incelenmesi
}

\author{
Kürşad Göv* \\ Gaziantep Üniversitesi, Havacılık ve Uzay Bilimleri Fakültesi, Uçak ve Uzay Mühendisliği Bölümü, 27310, Gaziantep, Türkiye
}

\section{Ö N E C I K A N L A R}

- $\quad$ EEİ yöntemi ile Havacıllk malzemelerinin delinmesi

- EEI'de soğutma sıvısı olarak musluk suyu, saf su ve kerosen kullanımı

- $\quad$ EEİ performans parametrelerinin incelenmesi

Makale Bilgileri

Geliș: 09.08.2016

Kabul: 20.11 .2016

DOI:

$10.17341 /$ gazimmfd.300621

Anahtar Kelimeler:

Elektro erozyon ile delik delme,

titanyum alaşımı,

nikel alaşımı,

kerosen,

saf su

\section{ÖZET}

Bu çalışmada, havacılık malzemelerinden titanyum alaşımına (Ti6Al4V) ve nikel alaşımına (İnkonel 718), tek oluklu pirinç elektrotla, içerisinde farklı tiplerde soğutma sıvısı (musluk suyu, saf su ve kerosen) kullanılarak elektro erozyon ile delik delme (EEDD) işlemi uygulanmıştır. Çalışmada elektro erozyon parametreleri titanyum ve nikel alaşımları için yapılan ön deneylerde belirlenerek sabit tutulmuş ve soğutma sıvısı çeşitlerinin malzeme kaldırma oranı (MKO), elektrot aşınma oranı (EAO), yüzey pürüzlülüğü $\left(\mathrm{R}_{\mathrm{a}}\right)$, beyaz katman tabakası $(\mathrm{BKT})$, çap büyümesi $(\mathrm{ÇB})$ ve çıkışta konikleşme gibi EEDD performans parametreleri üzerine etkileri incelenmiştir. Farklı soğutma sıvılarının kullanımı havacılık malzemelerinin EEDD performanslarını etkilediği belirlenmiştir. Ti6Al4V alaşımı için de-iyonize su kullanımının tüm performans parametreleri için en iyi sonuçları verdiği, İnkonel 718 malzemesi için de musluk suyu ve kerosenin de-iyonize suya göre daha iyi sonuçlar verdiği tespit edilmiştir.

\section{Experimental investigation of the effects of the coolant on the performance parameters of electrical discharge drilling of some aerospace materials}

\section{H I G H L I G H T S}

- $\quad$ Drilling aerospace materials by EDM

- Using tap water, distilled-water and kerosene as a coolant in EDM

- Investigation of the EDM performance parameters

Article Info

Received: 09.08.2016

Accepted: 20.11 .2016

DOI:

10.17341/gazimmfd.300621

Keywords:

Electro discharge hole

drilling,

titanium alloy,

nickel alloy,

kerosene,

distilled water

\begin{abstract}
In this study, electrical discharge drilling (EDD) processes is applied to aerospace materials of Ti6Al4V and Inconel 718 by using single channel brass electrode and different coolant types (tap water, distilledwater and kerosene). In the study the electro erosion parameters kept constant according to the preexperiments' data for titanium and nickel alloys and the effect of the coolant types on the performance parameters such as material removal rate, electrode wear rate, surface roughness value, white layer thickness, overcut in diameter and taper at the tip was examined. Electro discharge drilling performance was effected by the coolant types for aerospace materials. It is concluded that the usage of the distilledwater for Ti6A14V alloy and the tap water and kerosene for Inconel 718 alloy gave the better results for all performance parameters.
\end{abstract}

\footnotetext{
* Sorumlu Yazar/Corresponding author: gov@gantep.edu.tr / Tel: +90 342360 1200-3527
} 


\section{GÍRIŞ (INTRODUCTION)}

Elektro erozyon ile işleme (EEI) yöntemi, elektrik akımının elektrot üzerinden iş parçasına aktarılması ile iş parçasından talaş kaldırma işlemi olarak tanımlanabilir. Bu yöntem, dalma EEİ, tel EEİ ve delik EEİ olmak üzere üç farklı metot olarak kullanılmaktadır. EEİ ile delik delme işlemi, diğer metotlarda kullanılan elektriksel parametreler ile döner elektrotun elektrik akımını iş parçasına aktarmasıyla gerçekleşir. Basınçlı soğutma sıvısının elektrot içerisinden işleme bölgesine uygulanması sonucu iş parçası ve elektrot soğutulurken kopan talaşlarda işleme yüzeyinden tahliye edilmektedir. $\mathrm{Bu}$ yöntem ile 0,2-3,0 $\mathrm{mm}$ aralığındaki çaplarda ve çok büyük delik derinliğii/delik çapı oranlarında delikler, metalik her türlü malzemeye deline bilmektedir. Yüksek mukavemet, sıcaklık dayanımı, aşınma direnci gibi özelliklere sahip süper alaşımlar günümüz havacılık ve uzay sanayinde yaygın olarak kullanılmaktadır. Bu süper alaşımlardan nikel alaşımı İnkonel 718 jet motorunun yüksek basınç ve sıcaklığa maruz kalan yanma patlama bölgesinde, titanyum alaşımı olan Ti6Al4V ise yüksek mukavemetin gerekli olduğu kompresör bölgesinde kullanılmaktadır. $\mathrm{Bu}$ süper alaşımlardan imal edilen parçaların çalışma şartlarında ömürlerinin uzatılması ve performanslarının arttırılması için kullanım esnasında soğutulmaları gerekmektedir. $\mathrm{Bu}$ soğutma işlemi de üzerlerine çok sayıda soğutma deliğinin açılmasıyla gerçekleştirilmektedir. Uzay ve havacılık sanayisinde yaygın kullanılan ve geleneksel yöntemlerle işlenmesi zor malzemeler olan nikel ve titanyum alaşımlarının tek ve çok oluklu elektrot kullanılarak elektro erozyon ile delik delme performanslarının kıyaslamalı deneysel çalışmaları Yılmaz ve arkadaşları tarafindan gerçekleştirilmiştir [1]. Türbin kanatçıklarına EEİ yöntemi ile soğutma deliklerinin delinmesi Boccadora ve arkadaşları tarafından çalışılmıştır. EEİ parametrelerinin optimize edilmesiyle MKO ve EAO değerleri iyileştirilmiş ve beyaz katman tabakası kalınlığ azaltılarak yüzey kalitesi iyileştirilmiştir [2]. Süper alaşımların, farklı EEİ yöntemleriyle işlenmesinde, EEİ parametrelerinin performans parametrelerine etkilerinin incelenmesi üzerine yapılan bazı çalışmalarda; yüzey kalitesi, yüzey geometrisi ve beyaz katman tabakası [3], yüksek boşalım enerjisinin performans üzerine etkisi [4], beyaz katman tabakası kalınlığının boşalım süresi ve boşalım akımı ile doğrudan ilişkili olduğu [5], yorulma dayanımı [6], $\mathrm{Cu}-\mathrm{Cr}$ toz metal elektrot kullanımı [7] gibi konular çalışılmıştır. Ayrıca EEİ yönteminin, matematiksel modellemesi ve parametre optimizasyonu Y1lmaz ve arkadaşları tarafından [8], işleme mekanizmasının isıl modellenmesi ise Çoğun ve arkadaşları tarafından [9] çalışılmıştır. EEİ yöntemi ile mikro deliklerin deline bilirliği Öpöz ve arkadaşları tarafindan çalışılmış [10] ve açık ve kör uçlu mikro deliklerin iş parçası geometrisi ve ölçü toleransları kıyaslanmıştır [11]. Göv tarafından yapılan, pirinç ve bakır elektrotların tek ve çok kanallı tiplerinin kullanıldığı deneysel çalışmada, tek kanallı pirinç elektrotun çok kanallı pirinç ve bakır elektroda göre işleme hızının yüksek, elektrot aşınmasının düşük, yüzey kalitesinin daha iyi ve beyaz katman tabakası kalınlığının daha düşük olduğu ortaya konulmuştur [12]. Elektro erozyon ile delik delme işleminde, performans çıtıtlarını elektrik parametreleri kadar soğutma sıvısı parametreleri de önemli oranda etkilemektedir. Elektro erozyon ile işlemede çelik iş parçasına bakır elektrot kullanılarak gerçekleştirilen çalışmada soğutma sıvısı; saf su, musluk suyu, tuzlu ve gliserinli suyun performans parametrelerine etkileri deneysel olarak çalışılmıştır [13]. EEİ işleminde, musluk suyu ve de-iyonize suyun sade ve farklı oranlarda karışımının performans üzerine etkilerinin araştırıldı̆̆ çalışmada, musluk suyu kullanıldığında en iyi malzeme kaldırma oranına ulaşıldığı rapor edilmiştir [14]. EEİ işleme performansının artırılması için yapılan çalışmada, soğutma sıvısına şeker ve alkol gibi organik katkı maddeleri eklenmiş ve EEİ soğutma sıvısı ile kıyaslanmıştır. Organik katkı maddelerinin malzeme kaldırma oranını iki katına çıkarttığı gözlemlenmiştir [15]. Kerosen ve de-iyonize suyun soğutma sıvısı olarak kullanıldığı deneysel çalışmada, de-iyonize suyun kerosene oranla daha fazla malzeme kaldırdığı ve daha düşük elektrot aşınması gerçekleştiği rapor edilmiştir [16]. Dalma EEİ yöntemi için organik katkılı soğutma sıvısı ile de-iyonize suyun kıyaslamalı deneysel çalışmasında, organik katkılı soğutma sivisının de-iyonize suya oranla daha fazla malzeme kaldırdığı rapor edilmiştir [17]. Beyaz katman tabakasının metalografik incelemesinin yapıldı̆̆ 1 dalma EEİ işleminde, iş parçası, elektrot tipi ve soğutma sıvilarının etkileri incelenmiştir. Soğutma sıvısı olarak yağ kullanımının demir karbür $\left(\mathrm{Fe}_{3} \mathrm{C}\right)$ oluşumunu arttırdığ 1 , su kullanımının ise karbür oluşumunu engellediği görülmüştür [18]. Oishi ve arkadaşları mikro EEİ delik delme işleminde musluk suyu ve keroseni soğutma sıvısı olarak kullanmış ve performans üzerine etkilerini incelemişlerdir. Su kullanımının malzeme kaldırma oranını arttırdı ğı, elektrot aşınmasını azalttığı ve karbür oluşumunu engellediği rapor edilmiştir [19]. Soğutma sıvısında oksijen çözünmüş soğutma sıvısının delik EEİ performans parametreleri üzerine etkileri Göv tarafından çalışılmıştır. Suda çözünen oksijen miktarının artması EEİ performansını arttırmış ve geometrik toleransları iyileştirmiştir [20]. Sarkar ve arkadaşları titanyum alaşımı Ti6Al4V iş parçasına mikro EEİ yöntemi ile işlemeler yapmış ve soğutma sıvılarının etkilerini incelemişlerdir. Kerosen, de-iyonize su, bor karbür katk1lı kerosen ve bor karbür katkılı de-iyonize suyun soğutma sıvısı olarak kullanıldığı deneysel çalışmada, malzeme kaldırma oranı, elektrot aşınması, çapta büyüme ve yüzey kaliteleri performans parametresi olarak incelenmiştir. MKO ve EAO'nın de-iyonize su kullanıldığında kerosene oranla daha fazla olduğunu, bor karbür katkısının deiyonize suda MKO'nı arttırdığı, kerosende ise EAO'nı azalttığ1 gösterilmiştir [21]. Kumar ve arkadaşları grafit tozu katkı1ı soğutma sıvısı ile Ti6A14V alaşımına EEI işlemi uygulamış ve performans parametreleri incelenmiştir. EEI performans parametrelerinin grafit tozu katkı oranına ve boşalım akımına bağlı olduğunu rapor 
etmişleridir [22]. Ti6A14V'nin iş parçası olarak kullanıldı ̆̆ çalışmada, bor karbür $\left(\mathrm{B}_{4} \mathrm{C}\right)$ tozu katkılı soğutma sıvısı ile EEİ işlemi gerçekleştirilmiş ve $\mathrm{B}_{4} \mathrm{C}$ katkısının artmasılyla MKO’nın arttığını ve elektrot aşınmasının azaldığı gösterilmiştir [23]. Karbon ve nişasta tozu katk1lı 1sıtılmış silikon yağının di-elektrik sıvı olarak kullanıldığı EEİ delik delme işleminde, karbon tozu katkılı silikon yağ1 kullanımının nişasta tozu katkılı silikon yağı kullanımına göre oldukça yüksek İ̈H değerleri verdiği rapor edilmiştir [24]. Yapılan literatür taramasında, EEİ delik delme işleminde, farklı soğutma sıvılarının havacılık ve uzay malzemelerinden Ti6Al4V ve İnkonel 718 süper alaşımlarının her ikisi için işleme performanslarına etkilerinin incelendiği ve kıyaslandığı bir çalışmaya rastlanılmamıştır. $\mathrm{Bu}$ çalışmada elektro erozyon işleme parametreleri sabit tutularak Ti6A14V ve İnkonel 718 malzemelerinin EEDD işleminde, soğutma sıvısı tiplerinin (musluk suyu, de-iyonize su ve kerosen) performans parametrelerine (malzeme kaldırma oranı, elektrot aşınma oranı, yüzey pürüzlülüğü, delik çapında büyüme, çıkışta konikleşme ve beyaz katman tabakasının kalınlı̆̆ 1 ) etkileri incelenmiştir.

\section{DENEYSEL ÇALIŞMA (EXPERIMENTAL STUDY)}

Deneyler, JS EDM AD-20 tipi elektro erozyon tezgâhında yapılmıştır. 5x10x20 mm ölçülerinde tel erozyon tezgâhıyla kesilerek hazırlanan Ti6A14V ve İnkonel 718 havacılık ve uzay malzemeleri deney numunesi olarak kullanılmıştır. Numunelerin $10 \mathrm{~mm}$ x $20 \mathrm{~mm}$ olan delik açılacak yüzeyleri sirasiyla 320,600, 1200, 2000 ve 3000 meş su zımparaları ile hazırlanmış ve $1 \mu \mathrm{m}$ elmas süspansiyon kullanılarak parlatılmıştır. Deneylerde $2 \mathrm{~mm}$ çapında tek kanallı pirinç elektrot kullanılmıştır. Delikler, birleştirilen parlatılmış yüzeylere dik ve ortalı olacak şekilde delinmiştir. 3'er tekrarlı gerçekleştirilen deneylerde her bir delik için 3'er ölçüm alınarak ortalamaları performans değerleri olarak kullanılmıştır. Tüm deneyler oda sıcaklığında $\left(22^{\circ} \mathrm{C}\right)$, musluk suyu, kerosen (EDM 10095 Macron coolant) ve saf suyun soğutma sıvısı olarak kullanılmasıyla gerçekleştirilmiştir. Bu çalışmada, Titanyum ve İnkonel alaşımlarının delinmesinde elektro erozyon parametreleri; akım şiddeti $(\mathrm{I})$, ark süresi $\left(\mathrm{T}_{\text {on }}\right)$, ark bekleme süresi $\left(\mathrm{T}_{\text {off }}\right)$ ve kapasitans (C) yapılan ön deneylerde tespit edilen en iyi performans çıktılarını sağlayan değerler esas alınarak ve sabit tutularak kullanılmıştır (Tablo 1). Deneylerde kullanılan havacılık ve uzay malzemelerinin kimyasal kompozisyonları Tablo 2'de verilmiştir. Bu çalışmada, elektro erozyonla delinen deliklerin geometrileri; çaptaki büyüme (ÇB) ve koniklik açısı, malzeme kaldırma oranı (MKO), ortalama yüzey pürüzlülüğü değeri $\left(R_{a}\right)$ ve beyaz katman tabakası kalınlığı (BKTK) performans parametreleri olarak alınmıştır.

Tablo 2. İş parçalarının kimyasal kompozisyonları (Chemical compositions of the workpiece)

\begin{tabular}{llll}
\hline \multicolumn{3}{c}{ Ti6Al4V } \\
\hline $\mathrm{Ti}$ & 89,464 & $\mathrm{O}$ & 0,18 \\
$\mathrm{Al}$ & 6,08 & $\mathrm{C}$ & 0,02 \\
$\mathrm{~V}$ & 4,02 & $\mathrm{~N}$ & 0,01 \\
$\mathrm{Fe}$ & 0,22 & $\mathrm{H}$ & 0,0053 \\
\hline \multicolumn{5}{c}{ İkonel 718 } \\
\hline $\mathrm{Ni}$ & 52,5 & $\mathrm{Al}$ & 0,6 \\
$\mathrm{Cr}$ & 19 & $\mathrm{Si}$ & 0,35 \\
$\mathrm{Fe}$ & 17 & $\mathrm{Mn}$ & 0,35 \\
$\mathrm{Nb}+\mathrm{Ta}$ & 5,125 & $\mathrm{Cu}$ & 0,30 \\
$\mathrm{Mo}$ & 3,05 & $\mathrm{C}$ & 0,08 \\
$\mathrm{Co}$ & 1,00 & $\mathrm{~B}$ & 0,006 \\
$\mathrm{Ti}$ & 0,9 & & \\
\hline
\end{tabular}

\subsection{Malzeme Kaldırma Oranı (Material Removal Rate)}

Elektro erozyon ile işlemede, iş parçasından birim zamanda kaldırılan malzeme miktarı malzeme kaldırma oranı olarak tanımlanır ve Eş.1'deki formül ile hesaplanır. EEİ, elektrot ile iş parçası arasında oluşan yüksek enerjili kıvılcımın iş parçasından ergitme ve buharlaştırma sonucunda parça koparma prensibine dayanmaktadır. EEI' de yüksek işleme hızı amaçlanmakta ve çalışmalar bu doğrultuda gerçekleştirilmektedir. $\mathrm{Bu}$ çalışmada iş parçaları deney öncesi ve sonras1 0,1 mg hassasiyetinde Shimadzu AUX220 elektronik tartı ile tartılmış, işleme süresi elektronik süreölçer ile ölçülmüştür. $\mathrm{Bu}$ ölçümler kullanılarak malzeme kaldırma oranı Eş. 1'de aşağıda hesaplanmıştır.

MKO $=\frac{\text { ilk ağırlık-son ağırlık }}{\text { işleme zamanı }} x 100 \quad\left(\frac{\mathrm{g}}{\mathrm{dk}}\right)$

Tablo 1. Deneylerde uygulanan EEİ parametreleri (Applied EDD parameters)

\begin{tabular}{lll}
\hline Sabit Uygulanan Parametreler & Ti6Al4V & İnkonel 718 \\
\hline Akım, I (Amper) & 10 & 10 \\
Ark süresi, $\mathrm{T}_{\text {on }}(\mu \mathrm{s})$ & 35 & 38 \\
Ark bekleme süresi, $\mathrm{T}_{\text {off }}(\mu \mathrm{s})$ & 18 & 20 \\
Kapasitans C $(\mu \mathrm{F}))$ & 1422 & 1422 \\
Gerilim (volt) & 30 & 30 \\
Elektrot dönme hızı (rev/min) & 200 & 200 \\
Soğutma sıvisı basıncı (bar) & 100 & 100 \\
Elektrot polarite & $(-)$ & $(-)$ \\
Değişken uygulanan parametreler & & \\
Soğutma sılvisı & Musluk suyu, Saf su, Kerosen \\
\hline
\end{tabular}




\subsection{Elektrot Aşınma Oranı (Electrode Wear Rate)}

Elektro erozyon ile işlemede, yüksek sıcaklık değerlerine sahip kıvılcımlar, iş parçasında malzeme kopartırken beraberinde elektrot malzemesinden de parça kopartırlar. EEİ parametreleri ve elektrot özelliğine bağlı olarak gerçekleşen bu olaya elektrot aşınması denilmektedir. EEDD işleminde düşük elektrot aşınması işlemin performansını arttırmaktadır bu sebeple düşük elektrot aşınması hedeflenmektedir. Bu çalışmada, elektrot aşınma oranı; kullanılan elektrotun işleme öncesinde ve sonrasında $0,1 \mathrm{mg}$ hassasiyetinde terazi ile tartılarak Eş. 2 ile hesaplanmıştır.

$\% \mathrm{EAO}=\frac{\text { ilk ağılık-son ağırlık }}{\text { ilk ağırlık }} \times 100$

\subsection{Konikleşme ve Çapta Büyüme (Taper and Overcut)}

Elektro erozyon ile hızlı delik delme işleminde elektriksel kıvılcımlar elektrotun uç kısmında yoğunlaşmaktadır. Bu kıvılcım yoğunlaşması elektrotun uç kısmının diğer bölgelere oranla daha hızlı aşınmasına ve uç kısmının konikleşmesine sebep olmaktadır. Elektrot başlangıçta düz ve keskin kenarlıdır (Şekil 1a). Aşınmadan dolayı işleme sırasında ilerleme yönünde konikleşmeye başlar (Şekil 1b). Elektrotun bozulması deliğin sonuna doğru deliğin de konikleşmesine neden olur (Şekil 1c). Bu durum mermi çıkıntısı olarak da adlandırılır.

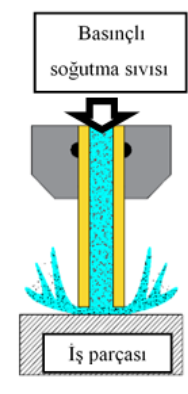

a

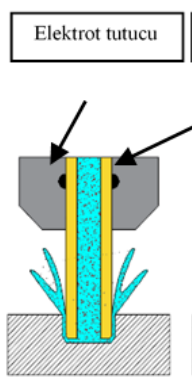

b

Elektrot Conta
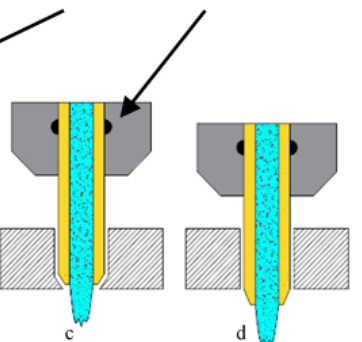

Şekil 1. Elektrot aşınması; (a) iş parçasına yaklaşma, (b) konikleşme başlangıcı, (c) tam konikleşme, (d) iş parçasından çıkış (Electrode wear; (a) access to workpiece, (b) taper starting, (c) full taper, (d) leave workpiece)

Elektrot ucunun iş parçasından çıkmasıyla elektrot ile iş parçası arasındaki soğutma ve tahliye ortadan kalktığı için Şekil 1d'deki durum hiçbir zaman gerçekleşmeyecek, yüzey yanacak veya elektrot iş parçasına kaynak olacaktır. İş parçasında oluşan koniklik Şekil 2'de verilen ölçüler doğrultusunda Eş. 3 kullanılarak hesaplanır;

$\theta=\tan ^{-1}\left(\frac{D_{t}-D_{b}}{2 h}\right)$

Bu eşitlikte; $\theta$ : koniklik açısı (radyan); $\mathrm{D}_{\mathrm{t}}$ : delik giriş çapı; $\mathrm{D}_{\mathrm{b}}$ : delik çıkış çapı ve $\mathrm{h}$ : koniklik yüksekliği olarak alınmıştır.

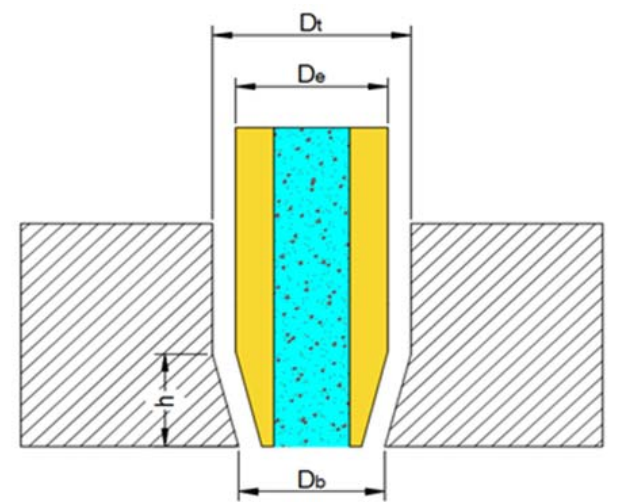

Şekil 2. Koniklik ve çapta büyüme (Taper and overcut)

Elektro erozyonla delik delme işleminde konikleşme oluşumu beraberinde iş parçası delik çapında büyüme de gerçekleşmektedir (Şekil 2). Delik çapında büyüme $\left(C_{b}\right)$, ortalama çap $\left(D_{0}\right)$ ile elektrot çap1 $\left(D_{e}\right)$ arasındaki farktan Eş. 4 kullanılarak hesaplanmaktadır. Delik çapında büyüme;

$C_{b}=D_{o}-D_{e}$

Ortalama çap, koniklik başlangıcına kadar olan kısımdan alınan ölçümlerin aritmetik ortalaması olarak hesaplanır. $\mathrm{D}_{0}$, Eş. 5 yardımıyla bulunmaktadır.

$D_{o}=\frac{\sum_{1}^{n} D_{a}}{n}$

\subsection{Delik Yüzeyinin İncelenmesi (Surface Observation of Hole Surface)}

Elektro erozyon ile delik delme işleminde performansı etkileyen en önemli parametrelerden birisi ortalama yüzey pürüzlülük değeri $\mathrm{R}_{\mathrm{a}}$ 'dır. Elektriksel parametrelere bağlı olarak değişen [25] ortalama yüzey pürüzlülüğü ölçümleri, Mitutoyo SJ 401 iğne uçlu yüzey pürüzlülüğü ölçüm cihazı ile yapılmıştır. Ölçümlerde örnekleme uzunluğu standart tablolardan $0,8 \mathrm{~mm}$ ve ölçüm uzunluğu $4 \mathrm{~mm}$ olarak seçilmiştir. İş parçasına aynı işleme şartlarında delinen 3 delikten 3' er ayrı ölçüm alınmış ve bu ölçümlerin ortalaması $\mathrm{R}_{\mathrm{a}}$ değeri olarak kullanılmıştır. Tüm elektro erozyon ile işlemelerde, sert ve kırılgan bir yapıya sahip olan beyaz katman tabakası oluşmaktadır. İş parçasından kopan bazı eriyik partiküller tekrar yüzeye tutunurlar, ani soğumanın da etkisiyle hızla katılaşarak iş parçası yüzeyinde beyaz katman tabakası oluştururlar. İşleme yüzeyi, iş parçasının bütününe oranla çok küçük bir kısmı oluşturduğundan, genleşme farklılıkları iş parçası yüzeyinde yoğunlaşarak 1sıl gerilmelerin oluşmasına sebep olmaktadır. Bu 1sıl gerilmeler iş parçası işleme yüzeyinde mikro çatlakların oluşmasına sebep olmaktadır [26]. EEDD işlemi ile delinmiş delik kesitlerinde taramalı elektron mikroskobu (SEM) kullanılarak görüntüler alınmış ve bu görüntüler üzerinde beyaz katman tabakası kalınlıkları ölçülmüş ve yüzey incelemesi yapılmıştır. 


\section{SONUÇLAR VE TARTIŞMALAR (RESULTS AND DISCUSSIONS)}

Tüm deneyler sabit oda sicaklığında $\left(22^{\circ} \mathrm{C}\right)$ ve farklı soğutma sıvıları kullanılarak yapılmıştır. Elektro erozyon parametreleri; akım şiddeti (I), ark süresi $\left(\mathrm{T}_{\text {on }}\right)$ ark bekleme süresi $\left(\mathrm{T}_{\text {off }}\right)$, ve kapasitans $(\mathrm{C})$, sabit tutulmuş ve soğutma sivisının performans parametrelerine etkileri incelenerek yorumlanmıştır.

\subsection{Malzeme Kaldırma Oranı (Material Removal Rate)}

Malzeme kaldırma oranı, her iki süper alaşımlı malzeme için farklı soğutma sıvılarının kullanılmasından farklı seviyelerde etkilenmiştir (Şekil 3).

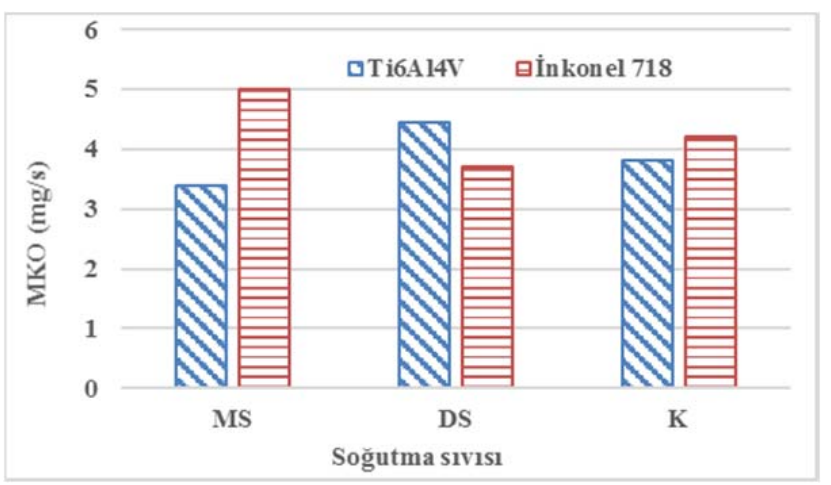

Şekil 3. Malzeme kaldırma oranı (Material removal rate)

Titanyum alaşımı Ti6A14V malzemesine uygulanan EEİ delik delme işleminde de-iyonize su kullanımı ile en yüksek malzeme kaldırma oranı olan $4,33 \mathrm{mg} / \mathrm{s}$ 'ye ulaşılmıştır. Kerosen kullanımı, de-iyonize suyu takip ederek 3,80 mg/s olurken en düşük malzeme kaldırma oranı 200 mg/dk ile musluk suyunda gerçekleşmiştir. Musluk suyuna oranla deiyonize su kullanımı malzeme kaldırma oranını \%30 mertebesinde arttırmıştır. Aynı şartlarda nikel alaşımı İnkonel $718,5 \mathrm{mg} / \mathrm{s}$ ile en yüksek malzeme kaldırma oranına musluk suyu kullanımı ile ulaşmıştır. Kerosen ve de-iyonize su kullanımında, musluk suyunu takiben sırasıyla 4,16 ve 3,66 mg/s MKO'na ulaşılmıştır. Sonuç olarak Ti6Al4V malzemesinin MKO, İnkonel 718'e göre daha düşük olduğu görülmüştür. $\mathrm{Bu}$ sonuç iki malzemenin ergime sıcaklık değerlerinin farklı olmasıyla açıklanabilir. Ergime sicaklığ $1650^{\circ} \mathrm{C}$ olan malzeme koparmak ergime sicaklığ $1336^{\circ} \mathrm{C}$ olan İnkonel 718 malzemesinden daha zordur. Aynı işleme sürelerinde ve EEİ parametrelerinde düşük ergime sıcaklığındaki İnkonel 718 malzemesinden daha fazla malzemenin kopması, akımının sıcaklık etkisiyle daha kolay ergime ve buharlaşma özelliği göstermesi ve Ti6Al4V malzemesinin ergime noktasına ulaşıncaya kadar İnkonel 718'in erimiş olmasıyla açıklanabilir. Ayrıca İnkonel 718'in 1s1l iletkenliğinin $(11,4 \mathrm{~W} / \mathrm{m} . \mathrm{K})$ Ti6Al4V $(6,7 \mathrm{~W} / \mathrm{m} . \mathrm{K})$ 'den daha yüksektir. Isıl iletkenlik değeri büyük olan Inconel 718 malzemesinde, deşarj esnasında oluşan 1sının yayılım oranı Ti6A14V'ya göre daha fazla olmakta ve MKO'nı arttırmaktadır. Musluk suyunun elektriksel iletkenliğinin $\left(510^{-3} \mathrm{~S} / \mathrm{m}\right)$ de-iyonize su $\left(5,510^{-6}\right.$
$\mathrm{S} / \mathrm{m})$ ve kerosene $\left(5,510^{-9} \mathrm{~S} / \mathrm{m}\right)$ göre çok yüksek olması, ayrıca İnkonel 718 malzemesinin elektriksel direncinin (0,125 Ohm-mm), Ti6Al4V malzemesine (0,178 Ohm-mm) göre düşük olması, deşarj miktarını arttırarak yüksek malzeme kaldırma oranına sebep olmuştur [27]. Ti6Al4V malzemesi için de-iyonize su kullanıldığına yüzeyde TiO oluşurken kerosen kullanıldığında TiC oluşmaktadır. Ergime sicaklığ $3150^{\circ} \mathrm{C}$ olan TiC'in işlene bilirliği, ergime sıcaklığ $1750^{\circ} \mathrm{C}$ olan TiO'e oranla çok daha zordur [28]. İş parçası yüzeyinde karbür ve oksit oluşumu MKO'nı doğrudan etkilemiştir. İşlem yüzeyinde karbür yapıların yerine oksit yapıların oluştuğu de-iyonize su kullanımı neticesinde hızlı bir talaş tahliyesi elde edilmiş ve en iyi MKO'na ulaşılmıştır.

\subsection{Elektrot Aşınma Oranı (Electrode Wear Rate)}

Elektrot aşınması, elektro erozyon ile işlemelerde yüksek sicaklık ve ani soğuma neticesinde iş parçasından malzeme ergiyerek koparken aynı zamanda elektrotta da ergime ve malzeme kaybı olarak açılanmaktadır. Bu aşınmanın miktarı elektrot malzemesine, elektriksel özelliklerine ve EEİ parametrelerine bağlıdır. EEİ yöntemiyle yapılan işlemelerin performansının iyi olarak değerlendirilmesi için elektrot aşınmasının düşük olması hedeflenmektedir.

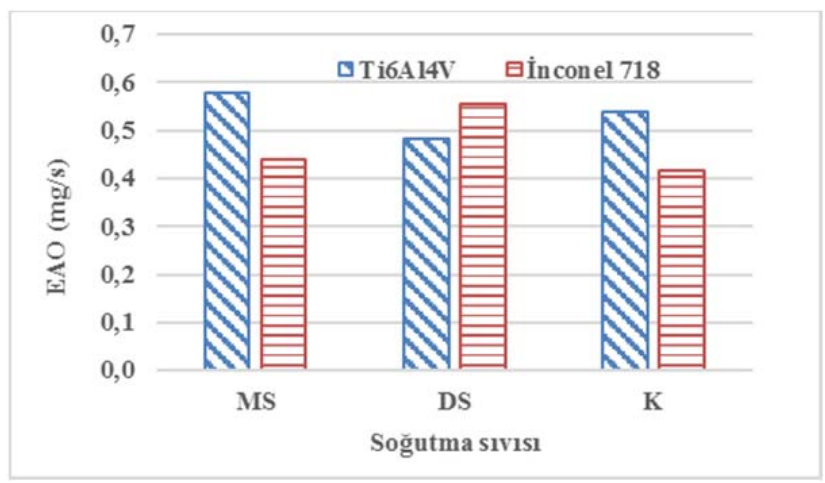

Şekil 4. Elektrot aşınma oranı (Electrode wear rate)

Elektrot ile iş parçası arasında oluşan kıvılcım atlaması esnasında, iş parçası elektrot ve soğutma sıvısı arasında tepkimeler olmakta ve bunların kimyasal bileşenlerine göre karbür veya oksit yapılar oluşmaktadır. Yüksek sıcaklıkta titanyum ve nikel alaşımlı malzemelerin tepkimeleri iş parçası malzemesine ve ergime sıcaklığına göre değişmektedir. Havacılık malzemelerinin EEDD işleminde, soğutma sıvısının EAO üzerine etkileri farklı olmuştur (Şekil 4). Ti6Al4V alaşımının EEDD yöntemiyle işlenirken de-iyonize su soğutma sıvisı olarak kullanıldığında, en düşük EAO'na ulaşılmıştır, kerosen ve musluk suyu kullanımı neredeyse aynı oranlarda elektrot aşınması gerçekleştirmişlerdir. Kimyasal yapısı hidrokarbon zinciri şeklinde olan kerosenin soğutma sıvısı olarak kullanıldığ EEDD işleminde, dar alanda yüksek sıcaklığa çıkılması neticesinde hidrojen ve karbon ayrışması gerçekleşmektedir ve ayrica musluk suyu ve de-iyonize su kullanıldığında hidrojen ve oksijen ayrışması gerçekleşmektedir [28]. Ti6A14V malzemesinin delinmesinde, iş parçası yüzeyinde 
oluşan TiC elektrotun yüzeyden parça kopartmasını zorlaştırarak EAO'nı arttırmıştır. İnkonel 718 malzemesinin EEDD yöntemiyle delinmesinde, musluk suyu ve kerosen kullanımı en düşük EAO'nı vermiştir. De-iyonize su kullanıldığında EAO $0,55 \mathrm{mg} / \mathrm{s}$ ile en yüksek değerini almıştır. EEDD yönteminde, soğutma sıvısı musluk suyu ve kerosen kullanıldığında, iş parçası ile elektrot arasında oluşan plazma kanalında, soğutma sıvısındaki iyonlar işleme süresini azaltmıştır. Isıl iletkenliği yüksek olan İnkonel 718 malzemesinin elektrota oranla daha hılı aşınması EAO'nı düşürmüştür.

\subsection{Delik Çapında Büyüme ve Konikleşme (Overcut and Taper)}

Elektro erozyon ile delik delme işleminde çapta büyüme ve konikleşme elektrot aşınması ile doğrudan ilişkilidir. Şekil 5 incelendiğinde, Ti6A14V süper alaşımında de-iyonize su kullanıldığında delik çapında en az büyüme gerçekleştiği, musluk suyu kullanıldığında ise en yüksek çap büyümesi gerçekleştiği görülmektedir. Bu malzemenin de-iyonize su kullanımında daha hızlı işlendiği Şekil 3'te gösterilmiştir. İşleme süresinin düşmesi etkileşim süresini düşürmüş ve delik çapında büyümeyi azaltmıştır. Aynı şekilde işleme hızı, kerosen kullanımında yüksek olan İnkonel 718 alaşımı için $110 \mu \mathrm{m}$ çapta büyüme değeriyle en iyi sonuç elde edilmiştir. Ti6Al4V malzemesi için elektrot aşınmasının en yüksek olduğu musluk suyu kullanımında en büyük koniklik değeri elde edilmiştir. Elektrotun iş parçasılyla etkileşiminin büyük bir kısmının uç kısmında gerçekleşmesi ve elektrot aşınmasının fazla olması, bu malzeme için musluk suyu kullanımında, en büyük konikleşme değeri 0,412 rad olmuştur. İnkonel 718 malzemesinin Şekil 4'te açıklandığı gibi musluk suyu ve kerosen kullanımında de-iyonize suya oranla daha düşük elektrot aşınması elde edilmiş ve aynı doğrultuda bu iki soğutma sıvısı için de düşük konikleşmenin (0,151 rad) oluştuğu belirlenmiştir. $\mathrm{Bu}$ durum Şekil 5'te gözlemlenmiştir. De-iyonize su kullanımı İnkonel 718 alaşımı için en büyük koniklik ( $0,38 \mathrm{rad})$ oluşumuna sebep olmuştur.

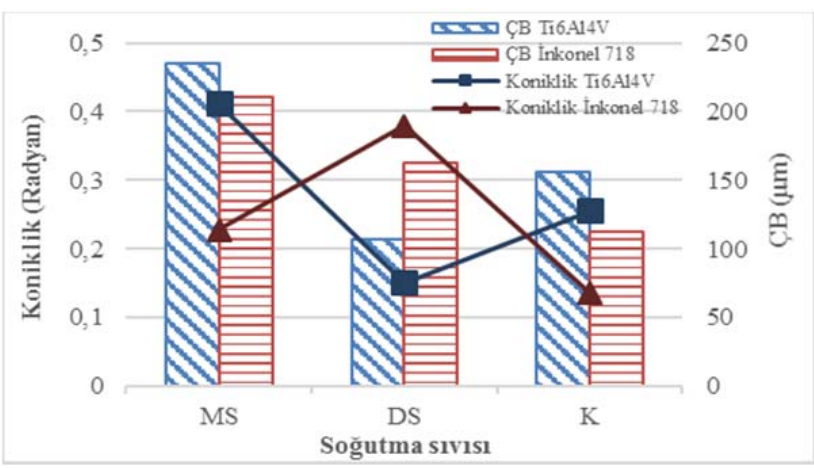

Şekil 5. Delik Çapında büyüme ve koniklik (Overcut and taper on hole diameter)

\subsection{Delik Yüzeyi Incelemesi (Surface Observation of hole surface)}

Elektro erozyon ile işlemede yüzey kalitesi, EEİ parametrelerine, elektrot-iş parçası etkileşimine ve kopan parçacıkların yeniden iş parçası yüzeyine yapışmasına bağlı olarak değişmektedir. Şekil 6' da EEDD işleminde, soğutma sıvısının, havacilık malzemelerinin yüzey kalitelerine etkisi, ortalama yüzey pürüzlülük değeri $\left(\mathrm{R}_{\mathrm{a}}\right)$ olarak verilmiştir.

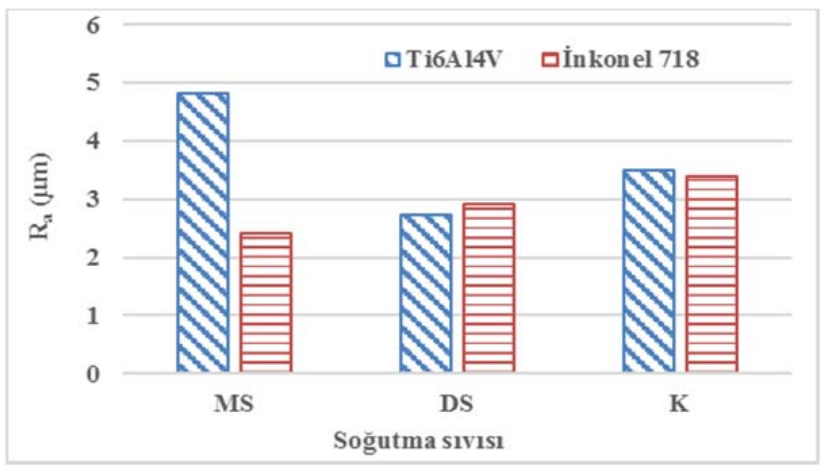

Şekil 6. Deliklerin Yüzey pürüzlülüğü değerleri (Surface roughness values of holes)

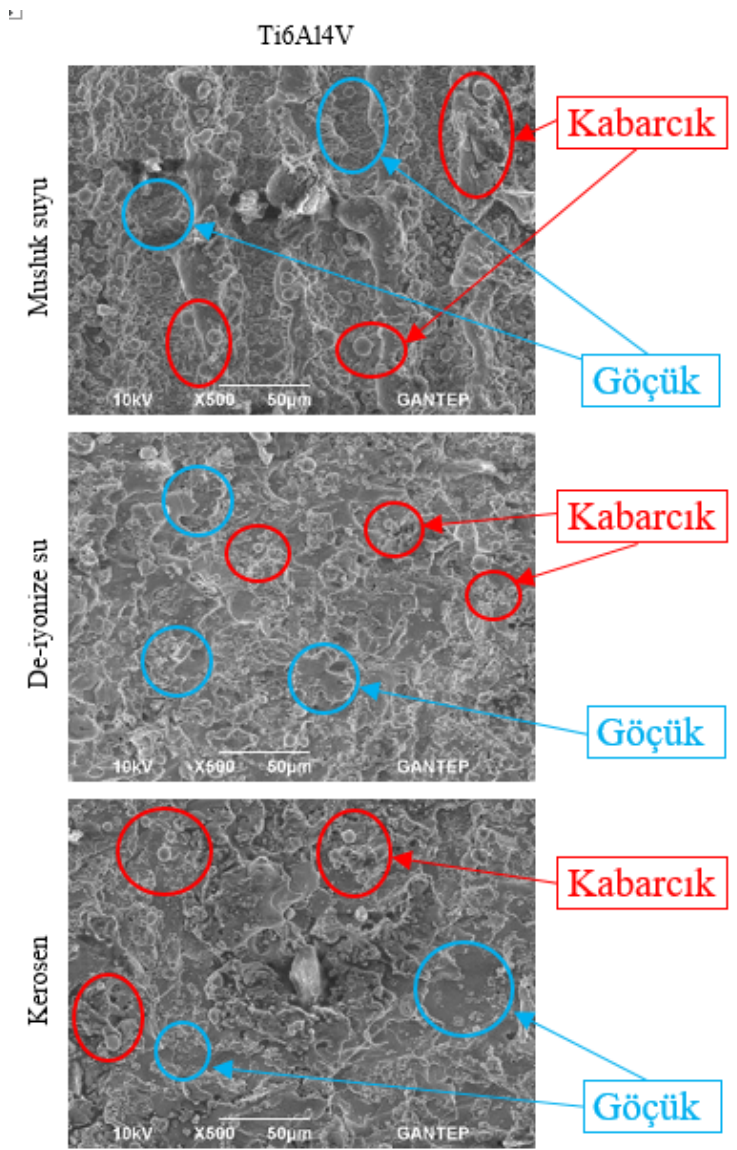

Şekil 7. Ti6Al4V SEM görüntüsü (SEM image of Ti6A14V)

Ti6Al4V alaşımı için en kaba delik yüzeyine $4,8 \mu \mathrm{m} \mathrm{R}_{\mathrm{a}}$ değeriyle musluk suyunda ulaşılmıştır. En iyi değere de 2,7 $\mu \mathrm{m} \mathrm{R}_{\mathrm{a}}$ ile de-iyonize su kullanımında ulaşılmıştır. İnkonel 718 alaşımı için en iyi değer $2,4 \mu \mathrm{m}$ değeri ile musluk suyunda elde edilmiştir. Kerosen kullanımında ise en kötü sonuç olan 3,4 $\mu \mathrm{m}$ değeri elde edilmiştir. Şekil 7'de SEM görüntülerinde incelenen Ti6A14V alaşımının EEDD işlemi 
sonrası elde edilen yüzeylerinde, musluk suyu kullanılan işlemlerde kabarcıkların büyük ve çok olduğu ve göçüklerinde belirgin olduğu görülmektedir. De-iyonize su kullanılan deneylerden elde edilen yüzeylerde küçük kabarcıklara ve göçüklere rastlanmıştır. Kerosende ise musluk suyuna nispeten daha az kabarcıklar görülmektedir. $\mathrm{Bu}$ kabarcıkların büyüklüğü ve çok olması ve ayrıca göçüklerin derinliği doğrudan yüzey pürüzlülüğünü etkilemektedir. SEM görüntüleri Şekil 6'da verilen yüzey pürüzlülüğü değerlerini desteklemektedir. Aynı şekilde Şekil 8'de verilen yüzey resimlerinin incelenmesi neticesinde, kerosen kullanılmış deliklerin SEM görüntülerinde kabarcıkların büyük ve göçüklerin derin olduğu tespit edilmiştir.

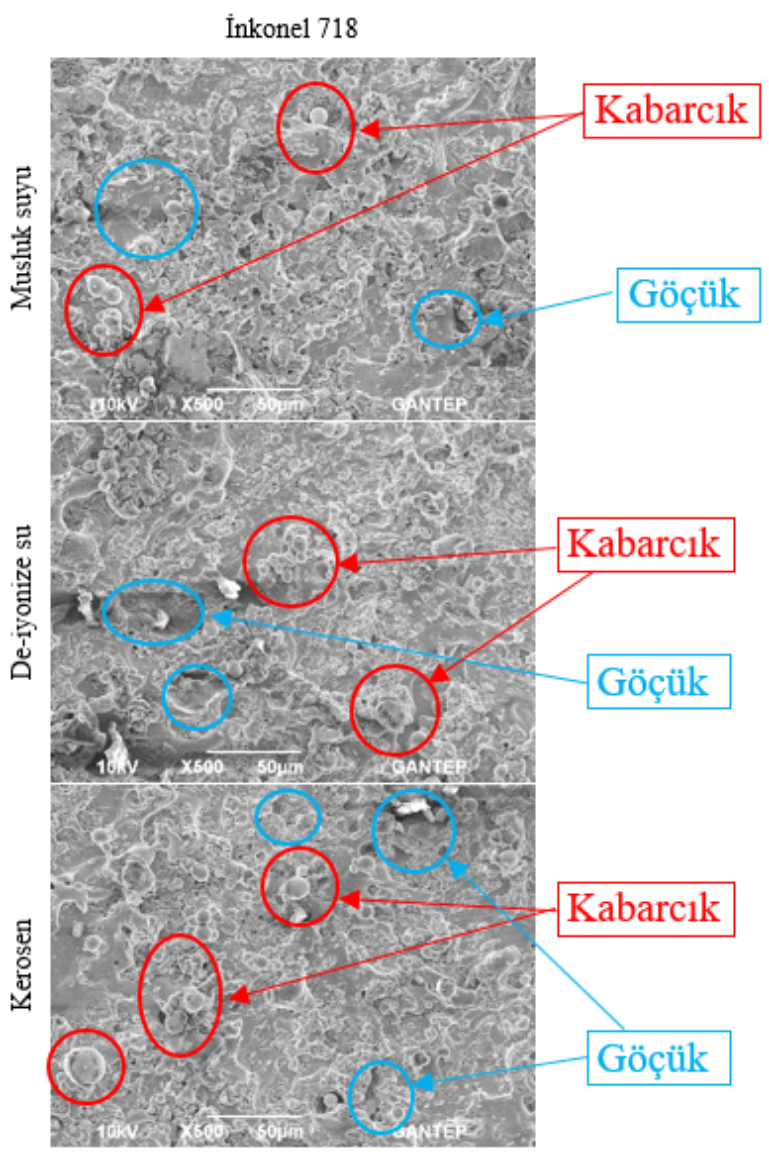

Şekil 8. İnkonel 718 SEM görüntüsü (SEM images of Inconel 718)

Bu görüntüler İnkonel 718 malzemesinin EEDD işleminde elde edilen $3,4 \mu \mathrm{m} \mathrm{R}_{\mathrm{a}}$ değerini desteklemektedir. İnkonel 718 alaşımı için en iyi yüzey görüntüsü musluk suyu kullanıldığında elde edilmiştir. Kabarcıklar yayvan ve yassı iken göçüklerin sı ̆ ve yayvan olduğu tespit edilmiştir. İş parçası yüzeyindeki iyileşmeler delik içerisinde muhtemel hava ve sıvı akışındaki kayıpları azaltacaktır. Aşırı 1sınma ve ani soğuma neticesinde iş parçasından kopan parçacıkların tekrar iş parçası yüzeyine yapışıp kaynak olmasıyla oluşan beyaz katman tabakası, çok sert ve gevrek bir yapıya sahiptir [29]. Mikro çatlaklar barındırması nedeniyle EE işlemlerinde oluşması istenilmeyen bir tabakadır. BKT kalınlığı, delik kesit yüzeyine dik alınan SEM görüntülerinden (Şekil 9) ölçülerek elde edilmiştir. BKT kalınlıkları Şekil 10'da verilmiştir. Ti6A14V alaşımı için en iyi BKT kalınlığı $26 \mu \mathrm{m}$ ile de-iyonize suda elde edilirken İnkonel 718 alaşımı için $20 \mu \mathrm{m}$ ile kerosen kullanımında elde edilmiştir. En büyük BTK değerleri ise Ti6Al4V için $65 \mu \mathrm{m}$, İnkonel için $44 \mu \mathrm{m}$ ile musluk suyunda elde edilmiştir. Bu elde edilen BKT kalınlıkları Şekil 7 ve Şekil 8'de verilen yüzey görüntüleri ile tutarlılık göstermekte ve elde edilen sonuçları desteklemektedir.
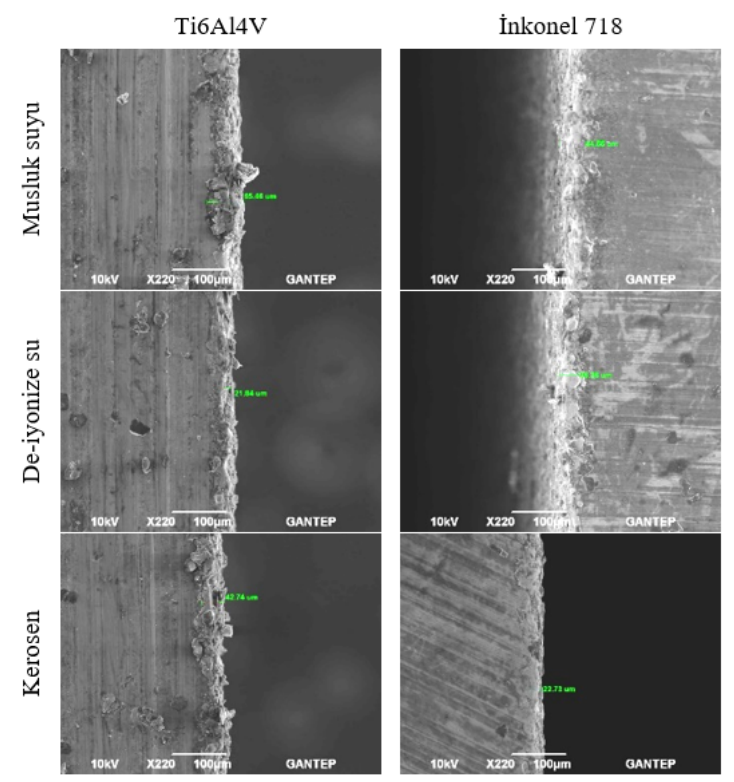

Şekil 9. BKT SEM görüntüleri (SEM images of WLT)

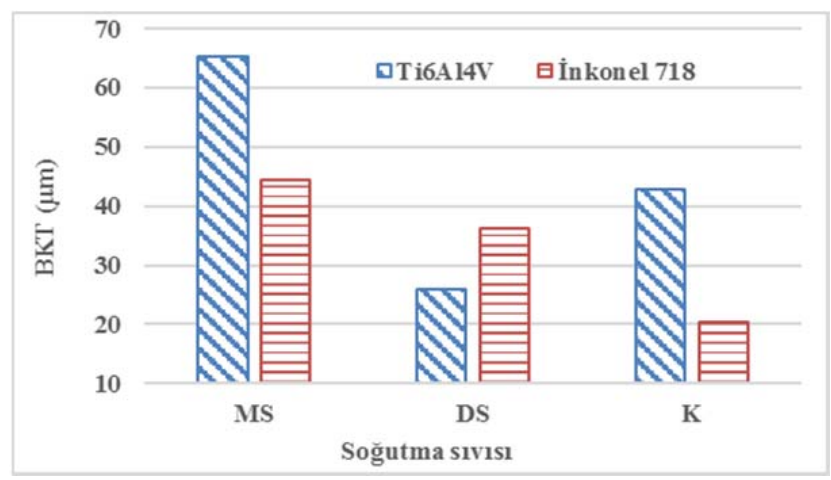

Şekil 10. Beyaz katman tabakası kalınlığı (White layer thickness)

\section{SONUÇLAR (CONCLUSIONS)}

EEDD işleminde musluk suyu, de-iyonize su ve kerosenin soğutma sıvısı olarak kullanıldığı bu çalışmada aşağıdaki sonuçlar elde edilmiştir.

Malzeme kaldırma oranında, Ti6A14V alaşımı için deiyonize suyun, İnkonel 718 alaşımı için ise musluk suyu kullanımının en iyi sonuçları verdiği tespit edilmiştir. 
Elektrot aşınma oranında, Ti6A14V süper alaşımı için deiyonize suyun en iyi sonucu verirken İnkonel 718 alaşımı için en kötü sonucu verdiği tespit edilmiştir. Çaptaki büyüme, Ti6A14V alaşımı için de-iyonize su kullanımında $107 \mu \mathrm{m}$, İnkonel 718 alaşımı için ise kerosen kullanımında $113 \mu \mathrm{m}$ seviyelerine düşmüștür. Ortalama yüzey pürüzlülük değeri Ti6A14V alaşımı için de-iyonize su kullanımında diğer soğutma sıvılarına oranla yarı yarıya düşmüş, İnkonel 718 alaşımı için ise musluk suyu kullanımı $\mathrm{R}_{\mathrm{a}}$ değerini 2,4 $\mu \mathrm{m}$ seviyelerine düşürmüştür. Beyaz katman tabakas1 kalınlığının en iyi değerleri, Ti6A14V için de-iyonize suda $26 \mu \mathrm{m}$, İnkonel 718 için kerosen ile $20 \mu \mathrm{m}$ seviyelerine düşürülmüş. $\mathrm{Bu}$ beyaz katman tabakası inceltilmesi iş parçası kullanım ömrünü uzatacaktır.

\section{KAYNAKLAR (REFERENCES)}

1. Yilmaz O., Okka M.A., Effect of single and multichannel electrodes application on EDM fast hole drilling performance, The International Journal of Advanced Manufacturing Technology, 51 (1-4), 185194, 2010.

2. Kliuev M., Boccadoro M., Perez R., Dal Bó W., Stirnimann J., Kuster F., Wegener K., EDM Drilling and Shaping of Cooling Holes in Inconel 718 Turbine Blades, Procedia CIRP, 42, 322-327, 2016.

3. Aspinwall D.K., Soo,S.L., Berrisford A.E., Walder G., Workpiece surface roughness and integrity after WEDM of Ti-6Al-4V and Inconel 718 using minimum damage generator technology, CIRP Annals - Manufacturing Technology, 57 (1), 187-190, 2008.

4. Li L., Guo Y., Wei X., Li W., Surface integrity characteristics in wire-EDM of Inconel 718 at different discharge energy, Procedia CirP, 6, 220-225, 2013.

5. Newton T.R., Melkote S.N., Watkins T.R., Trejo R.M., Reister L., Investigation of the effect of process parameters on the formation and characteristics of recast layer in wire-EDM of Inconel 718, Materials Science and Engineering: A, 513-514, 208-215, 2009.

6. Chen Z., Moverare J., Peng R.L., Johansson S., Surface Integrity and Fatigue Performance of Inconel 718 in Wire Electrical Discharge Machining, Procedia CIRP, 45, 307-310, 2016.

7. Gülcan O., Uslan İ., Yusuf U., Çoğun C., Effect of use of $\mathrm{Cu}-\mathrm{Cr} \mathrm{P} / \mathrm{M}$ electrodes on machining performance of electric discharge machining, Journal of the Faculty of Engineering and Architecture of Gazi University, 30 (3), 381-384, 2015.

8. Yilmaz O., Bozdana A.T., Okka M.A., An intelligent and automated system for electrical discharge drilling of aerospace alloys: Inconel 718 and Ti-6Al-4V, The International Journal of Advanced Manufacturing Technology, 74 (9-12), 1323-1336, 2014.

9. Sarıkavak Y., Çoğun C., Thermal modelling of machining mechanism in electrical discharge machining, Journal of the Faculty of Engineering and Architecture of Gazi University, 25 (3), 517-532, 2010.

10. Öpöz T.T., Ekmekci B., Erden A., An experimental study on the geometry of microholes in microelectric discharge machining, Materials and Manufacturing Processes, 24 (12), 1236-1241, 2009.

11. Ekmekci B., Sayar A., Öpöz T.T., Erden A., Geometry and surface damage in micro electrical discharge machining of micro-holes, Journal of Micromechanics and Microengineering, 19 (10), 105030, 2009.

12. Göv K., An Experimental Investigation of the Effects of Electrodes in EDM Hole Drilling Process, Politeknik Dergisi, 20, (2), Baskıda, 2017.

13. Erden A., Temel D., Investigation on the use of water as a dielectric liquid in EDM, in Proceedings of the 22nd International Machine Tool Design and Research Conference, 1981.

14. Jilani S.T., Pandey P.C., Experimetnal investigations into the performance of water as dielectric in EDM, International Journal of Machine Tool Design and Research, 24 (1), 31-43, 1984.

15. Masuzawa, T., Tanaka, K., Nakamura, Y. ve Kinoshita, N., Water-Based Dielectric Solution for EDM, CIRP Annals - Manufacturing Technology, 32 (1), 119-122, 1983.

16. Göv K., Influence of the Coolant on Performance of Electro Discharge Hole Drilling, Politeknik Dergisi, 20 (1), 2017.

17. König W., Jörres L., Aqueous Solutions of Organic Compounds as Dielectrics for EDM Sinking, CIRP Annals - Manufacturing Technology, 36 (1), 105-109, 1987.

18. Zhang Y., Liu Y., Ji R., Cai B., Study of the recast layer of a surface machined by sinking electrical discharge machining using water-in-oil emulsion as dielectric, Applied Surface Science, 257 (14), 59895997, 2011.

19. Kagaya K., Oishi Y., Yada K., Micro electro-discharge machining using water as a working fluid 2: Narrow slit fabrication, Precision Engineering, 12 (4), 213-217, 1990.

20. Göv K., Investigation of the effects of the dissolved oxygen in the coolant on the hole geometries drilled by electro erosion, Journal of the Faculty of Engineering and Architecture of Gazi University, 31 (2), 231-240, 2016.

21. Kibria G., Sarkar B.R., Pradhan B.B., Bhattacharyya B., Comparative study of different dielectrics for micro-EDM performance during microhole machining of Ti-6Al-4V alloy, The International Journal of Advanced Manufacturing Technology, 48 (5), 557-570, 2010.

22. Kolli M., Kumar A., Effect of dielectric fluid with surfactant and graphite powder on Electrical Discharge Machining of titanium alloy using Taguchi method, Engineering Science and Technology, an International Journal, 18 (4), 524-535, 2015.

23. Kolli M., Kumar A., Effect of boron carbide powder mixed into dielectric fluid on electrical discharge machining of titanium alloy, Procedia Materials Science, 5, 1957-1965, 2014.

24. Erdem O., Çoğun C., Urtekin L., Özerkan H.B., Uslan I., The effect of powder mixed and heated dielectric on 
drilling performance of electric discharge machining (EDM), Journal of the Faculty of Engineering and Architecture of Gazi University, 31 (3), 531-544, 2016.

25. Çoğun C., Kocabaş B., Özgedik A., Experimental and theoretical investigation of workpiece surface profiles in electrical discharge machining (EDM), Journal of the Faculty of Engineering and Architecture of Gazi University, 19 (1), 97-106, 2004.

26. Ergün Z.E., Çoğun C., Experimental investigation on workpiece surface characteristics in electric discharge machining (EDM), Journal of the Faculty of Engineering and Architecture of Gazi University, 21 (3), 427-442, 2006.
27. Kim C.H., Influence of the Electrical Conductivity of Dielectric Fluid on WEDM Machinability, Dept. of Mechanical Engineering, Dong-Eui University, Gaya-2 Dong, Pusanjin-Gu, Pusan, 614-714, 2004.

28. Chen S., Yan B., Huang F., Influence of kerosene and distilled water as dielectrics on the electric discharge machining characteristics of Ti-6A1-4V, Journal of Materials Processing Technology, 87 (1), 107-111, 1999.

29. Mohanty C.P., Mahapatra S.S., Singh M.R., An experimental investigation of machinability of Inconel 718 in electrical discharge machining, Procedia Materials Science, 6, 605-611, 2014. 
